ESTUDO DA CO-PIRÓLISE DE POLIPROPILENO PÓS-CONSUMO COM GASÓLEO DA BACIA DE CAMPOS

\title{
CO-PYROLYSIS OF POLYPROPYLENE WITH PETROLEUM OF BACIA DE CAMPOS
}

\author{
DE ASSUMPÇÃO, Luiz Carlos Fonte Nova'; MARQUES, Mônica Regina da Costa'; \\ CARBONELL, Montserrat Motas ${ }^{2}$
}

\author{
${ }^{1}$ Universidade do Estado do Rio de Janeiro, Instituto de Química, Laboratório de Tecnologia Ambiental, R. São \\ Francisco Xavier, 524, Pavilhão Haroldo Lisboa da Cunha, $3^{\circ}$ Andar, CEP 20559-900, Rio de Janeiro - RJ, \\ Brasil \\ e-mail: monica@pesquisador.cnpq.br \\ ${ }^{2}$ Petróleo Brasileiro S.A. - PETROBRAS, Av. República do Chile, 65 - $9^{\circ}$ Andar - Sala 904, CEP 20031-912, \\ Rio de Janeiro - RJ, Brasil \\ e-mail: montserrat@petrobras.com.br
}

\begin{abstract}
RESUMO
O presente trabalho buscou avaliar o processo de co-pirólise de resíduos de polipropileno com gasóleo, variando a temperatura e a quantidade de polipropileno no meio reacional. As amostras de polipropileno e gasóleo foram submetidas à co-pirólise térmica em atmosfera inerte, em sistema de leito fixo, sob fluxo constante de nitrogênio, variando a temperatura e a quantidade de PP no meio reacional. Os líquidos pirolíticos obtidos foram caracterizados por cromatografia gasosa, com o objetivo de avaliar a geração de frações na faixa da destilação do diesel. De uma maneira geral, pôde-se observar que o aumento da quantidade de PP no meio reacional favorece a redução do rendimento de líquido pirolítico e o aumento da quantidade de sólido gerado, efeito inverso ao do aumento da temperatura. Os resultados obtidos comprovam o potencial da co-pirólise como método de reciclagem química de artefatos de polipropileno pós-consumo.
\end{abstract}

Palavras-chave: resíduos, polipropileno, co-pirólise

\begin{abstract}
In this study, the process of co-pyrolysis of polypropylene (PP) residues with gas-oil was evaluated, varying the temperature and the amount of polypropylene fed to the reactor. The polypropylene samples and gas-oil were submitted to the thermal co-pyrolysis in an inert atmosphere, varying the temperature and the amount of PP. The influence of the gas-oil was evaluated carrying the co-pyrolysis in the absence of PP. The pyrolysed liquids produced by this thermal treatment were characterized by modified gaseous chromatography in order to evaluate the yield in the range of distillation of diesel. As a result, the increase of PP amount lead to a reduction in the yield of the pyrolytic liquid and to an increase of the amount of solid generated. The effect of temperature increase showed an inverse result. The results show that plastic residue co-pyrolysys is a potential method for chemical recycling of plastic products.
\end{abstract}

Keywords: waste, polypropylene, co-pyrolysis 


\section{Introdução}

Os plásticos são usados em grande
escala na produção de embalagens,
principalmente de produtos alimentícios, utensílios domésticos e eletrodomésticos, além de suas aplicações científico-tecnológicas e em diversas áreas da indústria. A popularização dos plásticos se deve, basicamente, ao seu baixo custo de produção, peso reduzido, elevada resistência e à possibilidade de seu uso na fabricação de peças nas mais variadas formas, tamanhos e cores, e com os mais diversos requisitos de especificação (transparência, dureza etc.) (DE SOUZA, 2002).

Por esses motivos, diversos materiais tradicionais como vidro, metais e fibras naturais foram sendo gradativamente substituídos por materiais poliméricos sintéticos. Alguns exemplos importantes desse processo são as embalagens de refrigerantes, que atualmente utilizam o poli(tereftalato de etileno) (PET) e a crescente utilização de polipropileno (PP) e plásticos de engenharia na indústria automobilística (DE SOUZA, 2002), substituindo peças de metal.

No entanto, a não degradabilidade no ambiente dos plásticos pós-consumo torna seu uso questionável. Uma vez dispostos no meio ambiente, tais materiais ocupam um considerável espaço, diminuindo o tempo de vida de aterros e lixões e agravando o problema da saúde pública nos centros urbanos.

Somado a isso, temos o potencial energético e químico contido em tais materiais, que podem ser reaproveitados através de sua reciclagem. Dessa forma, este trabalho teve como objetivo estudar a co-pirólise do polipropileno com gasóleo da Bacia de Campos, visando a obtenção de frações na faixa de destilação do diesel, importante na matriz energética mundial.

A demanda de materiais plásticos no mundo vem crescendo a taxas altíssimas, acima da taxa de crescimento do produto interno bruto (PIB) de alguns países. Os dados de NEGRI BOSSI (2004) apresentam projeções de demanda que indicam uma taxa de crescimento na ordem de $20 \%$ para o período de 2004 a 2009. No Brasil, o consumo aparente de plásticos em 2007 foi de 4,8 milhões de toneladas, mantendo uma tendência de crescimento (DE PAOLI, 2008).
A perspectiva de maior crescimento da economia e o reduzido grau de consumo per capita de plásticos no país apontam para um leque de possibilidades do setor. O consumo de plásticos per capita, em 2006, alcançou em 24,4 $\mathrm{kg}$ por habitante, inferior à média mundial e cerca de um quarto daquele verificado nos Estados Unidos (UNICAMP, 2008).

$O$ setor de embalagens (incluindo o setor alimentício) é o que representa a maior fatia de mercado dos plásticos. No ano de 2005, esse setor teve uma receita $R \$ 10$ milhões, com um crescimento previsto para 2006 de 3\% (ABRE, 2006).

O status atual de desenvolvimento requer uma igualdade nos pesos dos dois lados da balança. De um lado, está a sociedade em crescimento que requer a manutenção e/ou aumento dos níveis atuais de consumo de plásticos para não afetar a qualidade de vida alcançada. Do outro lado, está a biodiversidade e as condições ambientais que já estão sofrendo os efeitos desse cenário, uma vez que os resíduos plásticos representam uma fatia significativa do resíduo sólido mundial (MANCINI; ZANIN, 2004).

A "não degradabilidade" no ambiente e a vida útil muito curta dos artefatos plásticos têm sido fatores em que ambientalistas têm centrado suas campanhas. O avanço das legislações a nível nacional e internacional tem levado os produtores e processadores de resinas plásticas ao estudo de rotas alternativas para a disposição e/ou reaproveitamento desses resíduos.

Entre as diferentes técnicas estudadas, a reciclagem surgiu como uma das frentes mais promissoras para o tratamento de resíduos sólidos. Mundialmente, desde então, esse procedimento tem sido empregado e estudado (PLASTIVIDA, 2007). De um modo geral, a reciclagem de materiais plásticos utiliza uma menor quantidade de energia quando comparado ao processo convencional, considerando todo o processo desde a exploração da matéria-prima primária até a formação do produto final.

A pirólise, também conhecida como "termólise", é um tipo de reciclagem química onde ocorre decomposição química e térmica, produzindo moléculas menores que as presentes originalmente na carga. O termo pirólise vem do grego pyr (fogo) e lysis (desprendimento) (CARNEIRO, 2007). Na maioria dos processos, é realizada na ausência de ar por razões de 
segurança, qualidade dos produtos e rendimento (KAMINSKY; SCHEIRS, 2006).

Na pirólise é necessário que se faça um pré-tratamento do resíduo a ser processado, que pode consistir somente na separação do conteúdo e/ou no acabamento do mesmo. No caso de resíduos sólidos, podem ser citados ainda a trituração e a moagem, entre outros prétratamentos a serem aplicados como parte de um tratamento primário do material.

A principal vantagem da pirólise é a redução do volume dos resíduos, minimizando o problema da utilização de aterros sanitários acima da capacidade, problema esse que leva a uma diminuição da sua vida útil. A principal desvantagem é o custo operacional, relacionado principalmente ao reator e ao tratamento, necessário, dos gases efluentes (RECICLAGEM 2000, 200-).

Além disso, como já citado anteriormente, com relação a materiais plásticos e outros resíduos, devido à sua baixa condutividade térmica e a endotermicidade da reação de decomposição, esse processo consome uma alta quantidade de energia (CIOÎLTEU et al., 1999). Em processos que se utiliza ar, a oxidação parcial supre essa energia, porém os produtos da pirólise são diluídos pelos produtos da oxidação e da combustão (KAMINSKY; SCHEIRS, 2006).

Existem vários exemplos de sistemas pirolíticos em operação com diferentes tipos de tecnologias aplicadas para a retirada de produtos do processo. A transformação dos resíduos em subprodutos ocorre gradualmente à medida que os resíduos sólidos passam pelas diversas zonas de calor que constituem o reator pirolítico. Estados Unidos, Japão e China são os países que mais têm investido em pesquisa na área de pirólise, destacando-se a China em número de patentes depositadas (DE OLIVEIRA et al., 2008).

Segundo Aires e colaboradores (2003), a pirólise pode ser classificada em sistemas de alta temperatura e sistemas convencionais (baixa temperatura), em função das características dos processos.

Os sistemas convencionais (de baixa temperatura) podem ainda ser divididos em duas categorias: os destinados a produzir combustíveis gasosos e os de produção de combustíveis líquidos. A pirólise a baixas temperaturas promove predominantemente a despolimerização dos plásticos, isto é, o rompimento das cadeias poliméricas. Processos de pirólise rápida (flash ou flash pyrolysis) ocorrem em reator que opera a elevadas taxas de aquecimento, moderadas temperaturas finais de pirólise e curtos tempos de residência, tanto de resíduos quanto de produtos voláteis formados, visando minimizar as reações secundárias (ROCHA; PÉREZ; CORTEZ, 2004).

Os principais produtos do processo de pirólise são (MENEZES, 1999):

- gases, constituídos principalmente de hidrogênio, metano, monóxido de carbono, hidrocarbonetos leves e outros;

- líquidos, constituídos basicamente de hidrocarbonetos, alcoóis e ácidos orgânicos;

- resíduos sólidos, constituídos por carbono quase puro (char) e vidro, metais e outros materiais inertes (escórias).

Fatores como tipo de resíduos, tamanho das partículas submetidas ao processo, tipo de reator, temperatura e velocidade de variação da temperatura, cinética do processo, umidade presente nos resíduos, dentre outros, têm sido estudados como fatores que influenciam no processo pirolítico e nos subprodutos obtidos pelo tratamento (DE OLIVEIRA, 2006).

Existem vários estudos na linha de pirólise de plásticos e/ou misturas de plásticos, apontando para uma técnica promissora para a reciclagem desses materiais.

A co-pirólise é adição de mais de um material como carga do reator pirolítico. As vantagens estão relacionadas às condições de processamento (temperatura e pressão) que podem ser reduzidas. Segundo Miller e Shan (2000), a co-pirólise de poliolefinas com outros combustíveis tem se mostrado tecnicamente viável. 


\section{Materiais e Métodos}

As amostras de polipropileno (PP) virgem não sofreram nenhum tratamento prévio, sendo utilizadas nos testes de caracterização conforme recebidas. As amostras de PP pós-consumo (copos plásticos de polipropileno de $200 \mathrm{~mL}$ ) foram picotadas manualmente para posterior caracterização quanto às propriedades termogravimétricas e realização da co-pirólise. Para tal, tentou-se manter a mesma granulometria que, segundo De Oliveira (2006), é um dos fatores preponderantes no resultado da pirólise de plásticos.

As amostras de PP foram submetidas ao ensaio de análise térmica em DSC Pyris 1, da marca Perkin-Elmer, com aquecimento de $50^{\circ} \mathrm{C}$ até $200^{\circ} \mathrm{C}$, taxa de aquecimento $20^{\circ} \mathrm{C} / \mathrm{min}$ e fluxo de nitrogênio de $20,0 \mathrm{~mL} / \mathrm{min}$, em cápsulas de alumínio (ASTM E-537).

As análises termogravimétricas foram realizadas em instrumento TG da marca TA Instruments, modelo Q50, calibrado antes das análises com amostras-padrão de Alumel e Níquel. As análises das amostras, com massas entre 5 e $10 \mathrm{mg}$, foram realizadas por meio de uma rampa de aquecimento de 50 a $750{ }^{\circ} \mathrm{C}$ à velocidade de $10^{\circ} \mathrm{C} / \mathrm{min}$ em cadinho de platina, sob atmosfera de nitrogênio à vazão de 100,0 $\mathrm{mL} / \mathrm{min}$. (ASTM E-1868-04).

As amostras PP foram submetidas às análises de espectroscopia de infravermelho de reflexão total atenuada (IR-ATR) em instrumento Perkin Elmer Spectrum One FTIR, com acumulação de 32 e resolução de $4 \mathrm{~cm}^{-1}$.

As amostras de PP pós-consumo foram co-pirolisadas na presença de gasóleo em uma unidade de pirólise sob fluxo de nitrogênio, constituído basicamente de reator cilíndrico, fornalha, condensador de vidro e vaso recolhedor (Figura 1). Durante a pirólise da amostra contida no reator, o líquido combustível é recolhido por meio de imersão do condensador de vidro em banho de gelo e o gás combustível em vaso recolhedor. O sistema opera com base nas normas do Standard Test Procedure estabelecida no ASTM D 3907-92.

As amostras de PP pós-consumo foram pesadas, variando-se de $0,1 \mathrm{~g}$ até $1,0 \mathrm{~g}$ de PP. Paralelamente, pesou-se $1,0 \mathrm{~g}$ de gasóleo, mantendo-se esta quantidade em todos os testes de co-pirólise, inclusive aqueles onde não se adicionou o PP. A temperatura de pirólise foi de $400{ }^{\circ} \mathrm{C}$.

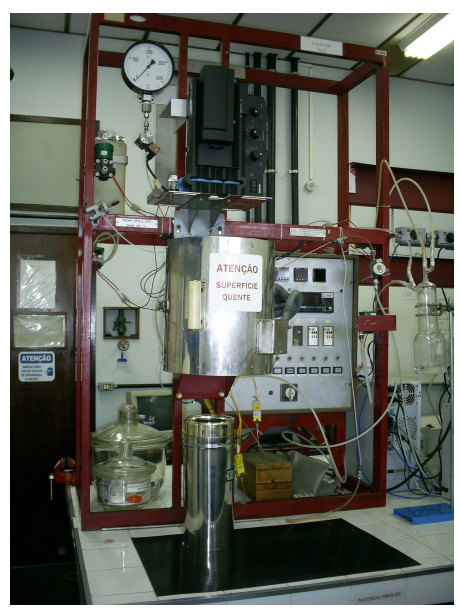

Figura 1 - Forno de pirólise utilizada nos testes de co-pirólise de polipropileno e gasóleo.

Transferiu-se o líquido do condensador de vidro para um frasco de amostragem, acrescentando-se $5 \mathrm{~mL}$ de n-hexano. As amostras foram armazenadas sob refrigeração a $4^{\circ} \mathrm{C}$, evitando, desta forma, a perdas por volatilização.

O efluente gasoso e o resíduo sólido obtidos na pirólise foram pesados, mas não analisados no presente estudo. Os líquidos da pirólise foram analisados por cromatografia em fase gasosa modificada. Os testes de pirólise foram realizados em duplicata e, caso houvesse divergência dos resultados, uma terceira análise foi realizada.

As análises do líquido pirolítico formado foram realizadas por destilação simulada de alta temperatura por cromatografia gasosa (High Temperature Simulated Destillation - HTSD), em cromatógrafo gasoso modificado, equipamento AC High Temp SIMDIS Analyzer, modelo HT750, com coluna capilar, seguindo metodologia ASTM D 7169 (Standard Test Method for Boiling Point Distribution of Samples with Residues Such as Crude Oils and Atmospheric and Vacuum Residues by High Temperature Gas Chromatography) (PINTO, 2002). 


\section{Resultados e Discussão}

As análises térmicas de calorimetria diferencial por varredura (DSC) permitiram avaliar o grau de cristalinidade das amostras e indicaram uma possível presença de aditivos na amostra de PP pós-consumo pela maior entalpia de fusão apresentada, se comparada a curva apresentada para o PP virgem, conforme mostra Figura 2.

As análises de TGA foram determinantes na escolha da faixa de temperatura a ser utilizada nos testes de co-pirólise de PP com gasóleo. Nesses testes também foi possível identificar uma variação do comportamento das curvas termogravimétricas das amostras de PP virgem e PP pós-consumo, indicando uma possível presença de aditivos no PP pósconsumo.

As análises de infravermelho foram importantes na identificação das bandas presentes nas amostras de PP virgem e PP pósconsumo que, pelo perfil dos espectros apresentados, indicam uma elevada pureza das amostras devido à preservação das características das bandas, que é típica de hidrocarbonetos alifáticos.

Segundo Carneiro (2007), o espectro de infravermelho da amostra de gasóleo apresenta as três regiões características de compostos parafínicos, semelhante às amostras de PP estudadas. Com base nos resultados desta análise, pode-se prever que a amostra de gasóleo utilizada nos testes de co-pirólise é composta, basicamente, de compostos hidrocarbonetos saturados e aromáticos.

Pelos testes de co-pirólise de PP com gasóleo, foi observado que o aumento da temperatura favoreceu o aumento da geração de líquido pirolítico e a redução do sólido formado. Já o aumento da quantidade de PP no meio reacional, favoreceu a redução do rendimento em líquido e o aumento do rendimento em sólido.

A Figura 3 apresenta o rendimento de líquido pirolítico formado durante a co-pirólise de PP com gasóleo a temperatura de $400^{\circ} \mathrm{C}$.

O líquido pirolítico obtido nas co-pirólises de PP com gasóleo foi submetido a cromatografia gasosa modificada. Esta metodologia permite determinar a distribuição dos pontos de ebulição de frações residuais até cerca de $720^{\circ} \mathrm{C}$, permitindo a análise de compostos com até 100 carbonos na composição, o que a torna mais adequada para amostras de composição desconhecida (AC ANALYTICAL CONTROLS, 2008).

Através dos resultados apresentados na cromatografia gasosa modificada, é possível correlacioná-los com dados de literatura. Assim, no presente trabalho, definiu-se a faixa de destilação entre 270 a $420^{\circ} \mathrm{C}$, correspondente as frações gasóleo leve atmosférico (GOL), gasóleo pesado atmosférico (GOP) e gasóleo leve de vácuo (GOV).

Os resultados obtidos pela cromatografia gasosa modificada são apresentados através de curvas de destilação simulada, onde podem ser observados os rendimentos, em massa, das faixas de ebulição. A Figura 4 apresenta os resultados para o líquido pirolítico obtido na pirólise do gasóleo a $400^{\circ} \mathrm{C}$.

\section{Conclusões}

Este trabalho avaliou a co-pirólise do polipropileno com gasóleo da Bacia de Campos, visando a redução do impacto causado pelo material polimérico pós-consumo e a obtenção de frações na faixa de destilação do diesel, importante na matriz energética mundial.

A análise por cromatografia gasosa modificada apresenta informações qualitativas e quantitativas do rendimento das frações destiladas dos líquidos pirolíticos. De uma maneira geral, pôde-se observar que o aumento da quantidade de PP, embora aumente o rendimento na faixa de destilação do diesel no líquido pirolítico, favorece a redução do rendimento de líquido pirolítico. Isso faz com que o rendimento de produto na faixa de destilação do diesel na co-pirólise não varie muito, sem apresentar uma tendência geral.

Os resultados do estudo indicam que a tecnologia de tratamento térmico por co-pirólise é válida para o tratamento de resíduos de PP, pois, além de minimizar o impacto ambiental causado pela disposição desse material de maneira inadequada, permite um melhor aproveitamento de um recurso natural não-renovável, o petróleo, através das frações obtidas no processo. 


\section{Agradecimentos}

À Faperj, ao CNPq e à Capes pelo suporte financeiro. À Petrobrás pela doação da unidade de pirólise e do gasóleo.

\section{Referências Bibliográficas}

1. AC ANALYTICAL CONTROLS. Apresenta informações sobre os analisadores AC High Temp SIMDIS. Disponível em: <http://www.analyticalcontrols.com/products/?

$\mathrm{nr}=64 \&$ site $=$ ac\&cat $=$ products $\&$ Xsubcat $=$ distillates $>$. Acesso em: 24 maio 2008.

2. AIRES, R.D.; LOPES, L.T; BARROS, R. M.; CONEGLIAN, C.M. R.; SOBRINHO, G. D.; TONSO, S.; PELEGRINI, R. Pirólise. In: III FÓRUM DE ESTUDOS CONTÁBEIS, s.n., 2003, Rio Claro, SP. Disponível em: <http://www.ceset. unicamp.br/lte/Artigos/3fec2416.pdf>. Acesso em: 25 de mar. 2008.

3. ASSOCIAÇÃO BRASILEIRA DE EMBALAGEM (ABRE). Informações sobre a Indústria de brasileira de Embalagens. Disponível em: <http://www.abre.org.br/index.php>. Acesso em: 4 nov. 2006.

4. CARNEIRO, D. S. Co-Pirólise de resíduos de polietileno com gás-óleo da Bacia de Campos. 2007. 91f. Dissertação (Mestrado em Química) Universidade do Estado do Rio de Janeiro, UERJ, RJ. 5. CIOCÎLTEU, S.; DARIE, H.; IOJOIU, E.; ONU, P.; VASILE, C. Thermal and catalytic decomposition of polyethylene and polypropylene. Journal of Analytical and Applied Pyrolylis, [S.I.], v. 49, p.145153, 1999.

6. DE OLIVEIRA, O. M. C.; DE SENA, A. R.; PEREIRA, L. A. G.; RODRIGUES, L.M. Reciclagem Química de Polímeros. 2008. 76f. Monografia (Especialização em Engenharia de Processamento de Petróleo) - Universidade Estadual do Rio de Janeiro, UERJ; Petróleo Brasileiro S.A. - PETROBRAS. Rio de Janeiro.

7. DE OLIVEIRA, M. L. Caracterização e Pirólise de Resíduos da Bacia de Campos: Análise dos Resíduos da P-40. 2006. 192 f. Dissertação (Mestrado em Química) - Universidade do Estado do Rio de Janeiro, UERJ. Rio de Janeiro.

8. DE PAOLI, M. A. Reciclagem Mecânica de Polímeros. In: I Seminário Reciclagem de Polímeros - PETROBRAS. Rio de Janeiro, s.n., 2008.

9. DE SOUZA, M. C. A. F. Estudo da Competitividade de Cadeias Integradas no Brasil: impactos das zonas de livre comércio. Nota Técnica Final, UNICAMP-IE-NEIT / MDIC / MCT /
FINEP, São Paulo, SP, 2002.

10. FERNANDES, L. D.; LIMA, E. L.; MATTOS, J. A.; VEJA, M. P. Análise de Unidade de Craqueamento Catalítico Fluido (FCC). In: Congresso Brasileiro de Engenharia Química - COBEQ, [S.I.], s.n., 2007. Disponível em: <http://www.ufscar.br/cobeqic07 /pdf/poster_iii/piii31.pdf>. Acesso em: 16 jun. 2008.

11. KAMINSKKY, W.; SCHEIRS, J. Feedstock Recycling and Pyrolysis of Waste Plastics: Converting Waste Plastics into Diesel and Other Fuels. Ed. John Wiley \& Sons, [S.I.], s.n., 2006.

12. MANCINI, S. D.; ZANIN, M. Resíduos Plásticos e Reciclagem: Aspectos Gerais e Tecnologia. EdUFSCar: São Carlos, SP, 143p., 2004.

13. MENEZES, R. A. Análise de projetos de tratamento por destruição térmica de resíduos sólidos urbanos e especiais. indicadores operacionais. Curso ABS/CEF, [S.I.], s.n., 1999. Disponível em: <http://www.kompac.com.br/pub licacoes/estado.htm>. Acesso em: 25 mar. 2008.

14. MILLER, S. J.; SHAH, N. Method for conversion of waste plastic to lube oil. United States Patent 6150577. USA, 2000. Disponível em: <http://www.freepatentsonline.com/6150577.html>.

Acesso em: 3 maio 2008.

15. NEGRI BOSSI. Editorial. Informações sobre demanda mundial de plásticos. [S.I.], 2004. Disponível em: <http://www.negribossi.com/Sys tem/8840/633481148125046232itlT.pdf>. Acesso em: 10 jun. 2008.

16. PINTO, U. B. Uso da Técnica de Destilação Simulada de Alta Temperatura para Extrapolação da Curva de Ponto de Ebulição Verdadeiro de Petróleos. Boletim Técnico Petrobras, Rio de Janeiro, RJ, v. 45, p. 343-349, 2002. Disponível em: <http://www2.petrobras.com.br/tecnologia/port/boletim tecnico/v45 n3-4 jul-dez-2002/pdf/8.pdf>. Acesso em: 15 jun. 2008.

17. PLASTIVIDA INSTITUTO SÓCIO-AMBIENTAL DOS PLÁSTICOS (PLASTIVIDA). Informações sobre os plásticos e reciclagem. Disponível em: $<$ http://www.plastivida.org.br/> e <www.plastivida.or g.br/reciclagem/rec_quimica.htm>. Acesso em: 10 maio 2008.

18. RECICLAGEM 2000. Pirólise. São Paulo, 200Disponível em: <http://www.geocities.com/reciclagem 2000/pirolise.htm>. Acesso em: 15 nov. 2006.

19. ROCHA, J. D.; PÉREZ, J. M.; CORTEZ, L. A. B. Aspectos Teóricos e Práticos do Processo de Pirólise de Biomassa. [Campinas, SP], s.n., 2004. Disponível em: <http://www.bioware.com.br>. Acesso em: 26 mar. 2008

20. UNICAMP. Unicamp e ABDI lançam Boletim de Conjuntura Industrial. São Paulo, SP, 2008. Disponível em: <http://www.unicamp.br/unicamp /divulgacao/BDNUH/NUH_10294/NUH_10294.html>. Acesso em: 11 jun. 2008. 


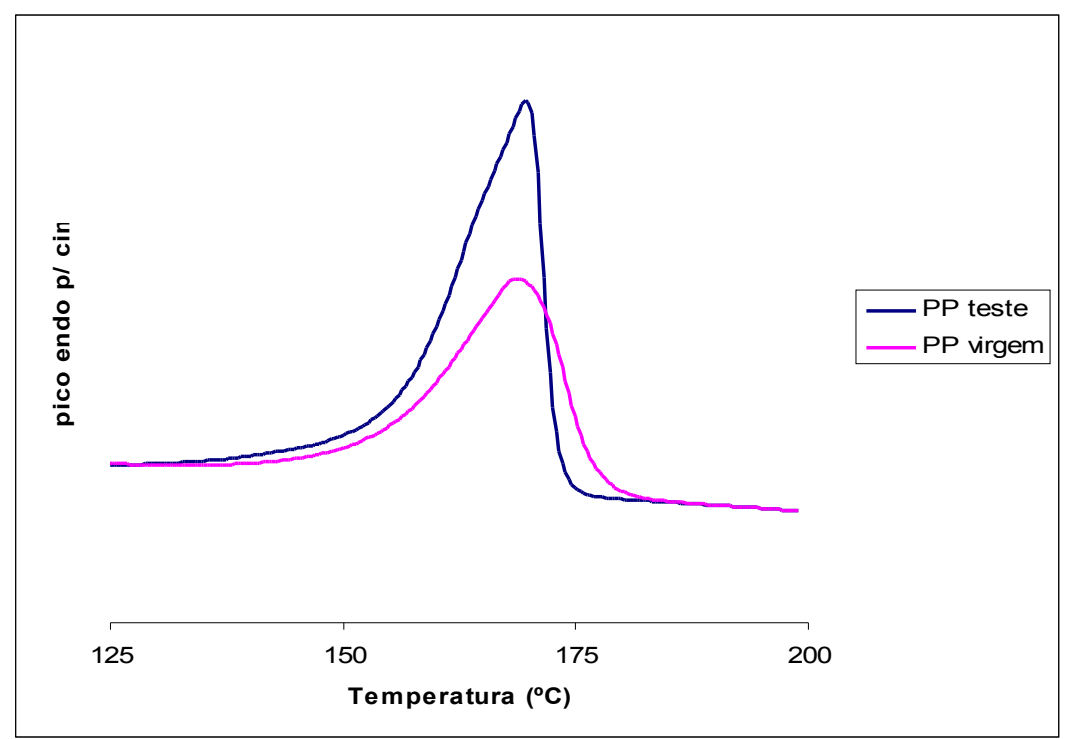

Figura 2 - Termograma comparativo das amostras de PP virgem e PP pós-consumo.

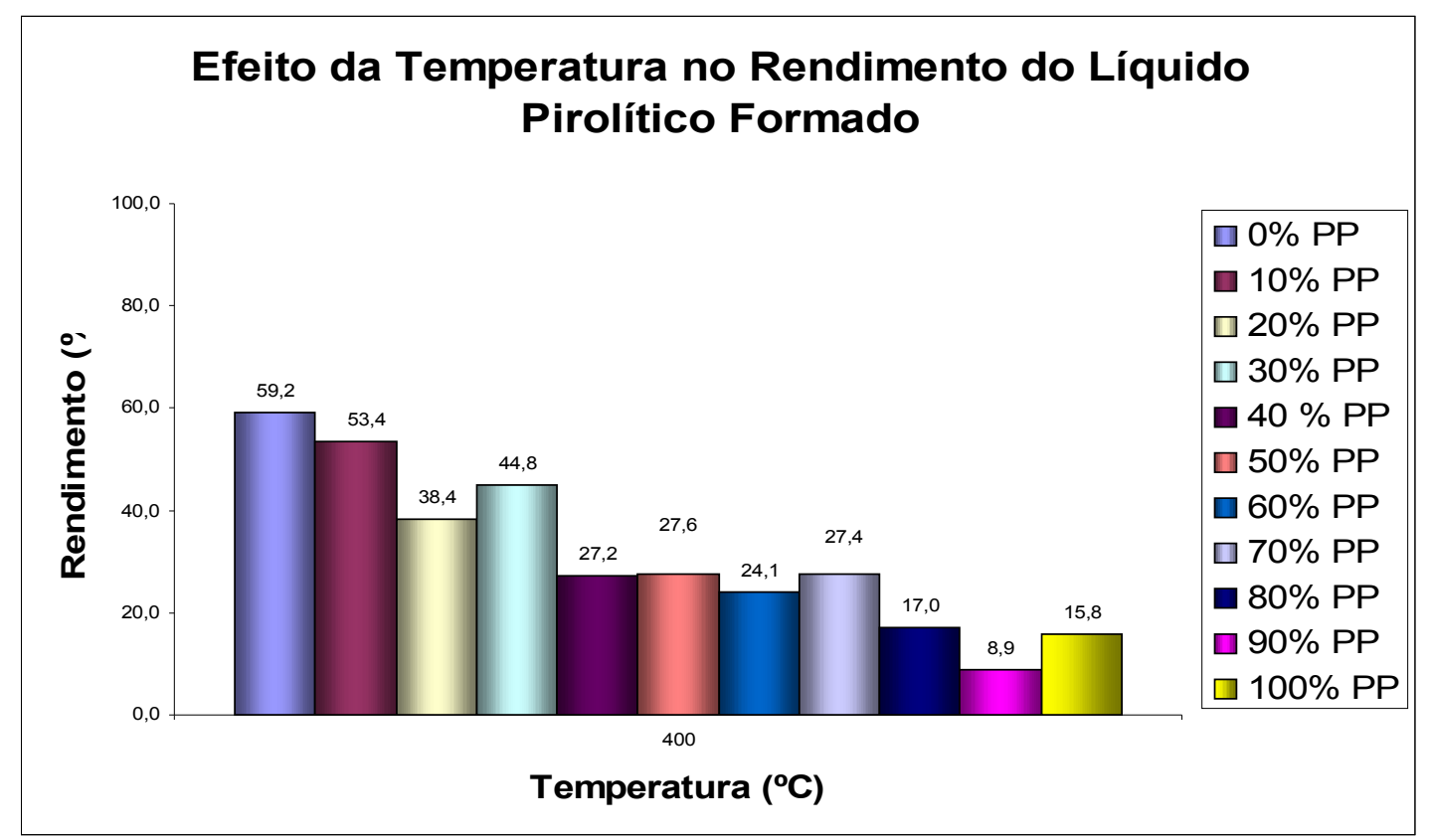

Figura 3 - Rendimento do líquido pirolítico formado na co-pirólise de PP com gasóleo a $400^{\circ} \mathrm{C}$. 


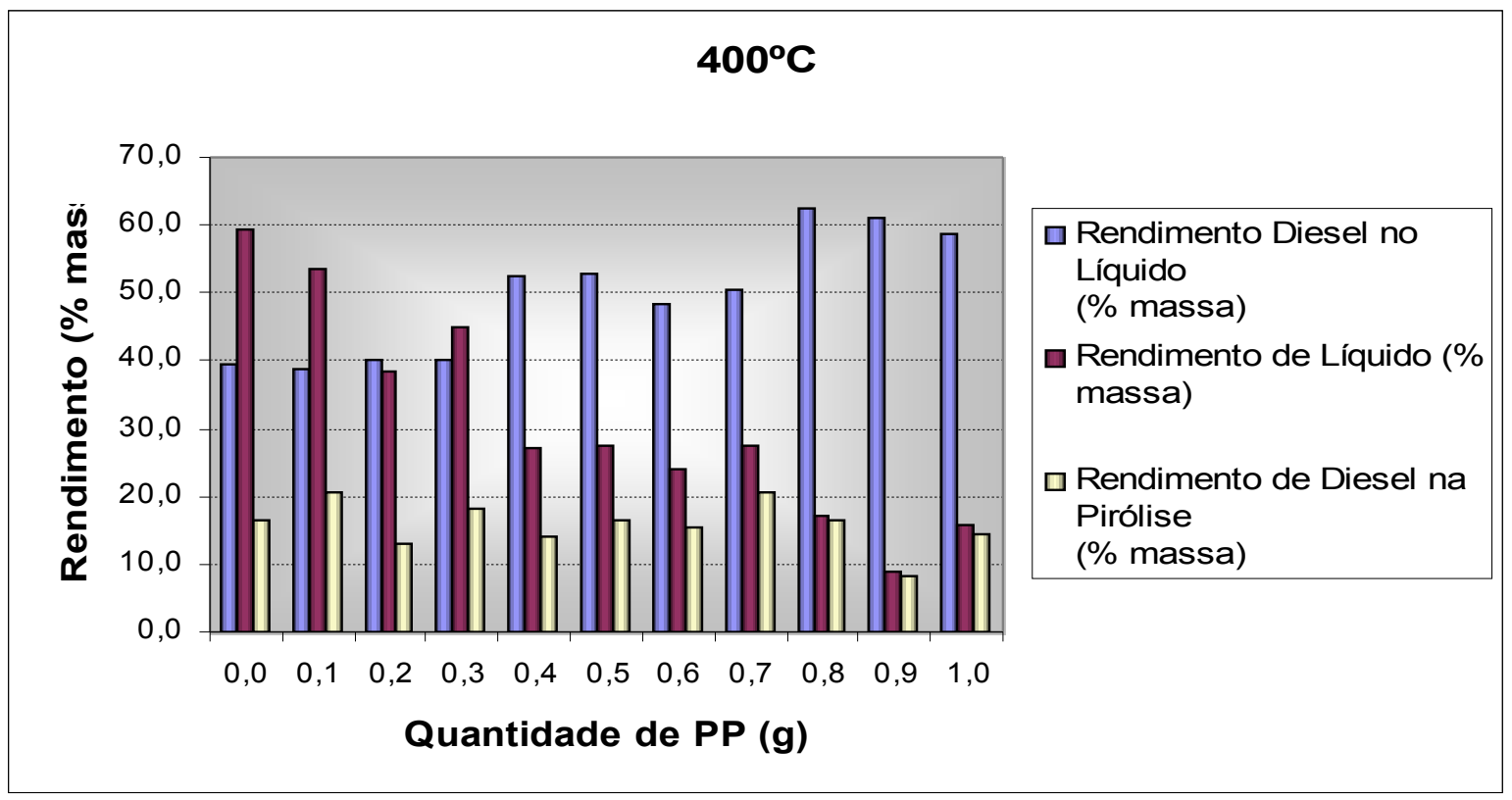

Figura 4 - Rendimento de diesel na Co-pirólise de PP com gasóleo a $400^{\circ} \mathrm{C}$. 